\title{
MICROESTRUTURA POROSA DE COQUE: INFLUÊNCIA DAS PROPRIEDADES DOS CARVÕES*
}

\author{
Anderson Nicolodi ${ }^{1}$ \\ Anderson Azevedo Agra ${ }^{2}$ \\ Bruno Deves Flores ${ }^{3}$ \\ Guilherme Liziero Ruggio da Silva ${ }^{4}$ \\ Antônio Cezar Faria Vilella ${ }^{5}$ \\ Eduardo Osório ${ }^{5}$
}

\begin{abstract}
Resumo
A microestrutura porosa do coque pode ser definida como a relação espacial entre a matriz carbonosa e seus poros. A formação da microestrutura ocorre durante o processo de carbonização dos carvões coqueificáveis. Portanto, o conhecimento das propriedades que governam a formação da microestrutura torna-se atrativa como uma ferramenta na escolha estratégica de carvões na composição de misturas para produção de coque. Neste trabalho coques laboratoriais foram produzidos por carvões com diferentes propriedades, visando a formação de coques com microestrutura com propriedades microestruturais distintas. A caracterização microestrutural foi realizada a partir de uma ferramenta de microscopia ótica associada a análise de imagens. A partir dos parâmetros obtidos na análise, foi estudado a influência das propriedades dos carvões nos parâmetros analisados. Além disso a convergência com outros modelos (MOF e CBI) foi estudada. Os resultados obtidos mostraram que carvões com estágio plástico desenvolvido e elevado teor de matéria volátil geram coques de alta porosidade e com poros de tamanho excessivo. Carvões ricos em componentes inertes apresentam microestrutura de baixa porosidade, composta de poros pequenos, no entanto, com poros de baixa circularidade. Os carvões com as melhores propriedades (critérios dos modelos MOF e CBI) resultaram nos coques com as microestruturas mais regulares, de baixa porosidade, com pequenos poros e com formatos adequado.
\end{abstract}

Palavras-chave: Coque metalúrgico; Microestrutura; Porosidade; Carvão.

\section{COKE MICROSTRUCTURE: INFLUENCE OF THE PARENT COAL PROPERTIES Abstract}

Coke microstructure can be defined as the spatial relationship between coke matrix and pores and it is formation occurs during the coal carbonization process. Understanding which parent coal properties rules the microstructure formation allow us to better estimate which changes in the coal blend could improve coke's quality. Laboratory cokes were produced by coals with different properties aiming to evaluate a large range of coke microstructure parameters. Coke microstructure characterization was carried out with an image analysis tool. The influence of the parent coal properties in the microstructure parameters was then evaluated. The results were also compared with the predicted in other coke quality models (MOF and $\mathrm{CBI}$ ). It was seen that high-volatile coals with high thermoplastic properties produce cokes with high porosity and large pore size. Coals with high inert content produce cokes with low porosity, small pore size, but unsuitable pore shape. The most suitable coke microstructure was produced with parent coals showing the best properties under MOF and CBI criterion.

Keywords: Coke; Microstructure; Porosity; Coal.

Engenheiro, Laboratório de Siderurgia (LaSid) da UFRGS, Porto Alegre, RS, Brasil.

Mestre, Laboratório de Siderurgia (LaSid) da UFRGS, Porto Alegre, RS, Brasil.

Doutor, Laboratório de Siderurgia (LaSid) da UFRGS, Porto Alegre, RS, Brasil.

Doutor, Gerdau Açominas, Ouro Branco, RS, Brasil.

Professor Dr., Laboratório de Siderurgia (LaSid) da UFRGS, Porto Alegre, RS, Brasil. 


\section{INTRODUÇÃO}

Nos processos de produção de ferro-gusa via alto-forno, o coque metalúrgico é uma matéria-prima fundamental, visto que exerce uma série de funções. Dentro destas funções, se destaca a função estrutural, onde o material é responsável por sustentar a carga do reator, fornecendo um leito permeável aos gases ascendentes. É essa função que torna o material insubstituível no processo, visto que nenhuma outra matéria-prima redutora consegue atender a resistência mecânica necessária para o processo.

Além da importância técnica, o coque metalúrgico apresenta grande impacto econômico nos processos siderúrgicos. Sendo que isto se deve aos elevados custos das matérias-primas do processo de coqueificação que, segundo estimativas, atingem mais de $40 \%$ do custo total de produção do ferro-gusa [1]. No contexto brasileiro, podemos atribuir o elevado custo a dois motivos: a diminuição constante da disponibilidade de carvões coqueificáveis de alta qualidade nas reservas mundiais e ao fato das usinas siderúrgicas brasileiras importarem 100\% dos carvões coqueificáveis.

Visando redução de custos no processo, realiza-se misturas para coqueificação contendo carvões com diferentes propriedades, bem como aditivos reativos ou inertes. Assim, para estimar e avaliar a qualidade dos coques gerados a partir dessas misturas, foram desenvolvidas uma série de metodologias que hoje são empregadas rotineiramente na indústria siderúrgica. No entanto, as metodologias empregadas apontam apenas a qualidade do coque, com limitação quanto à identificação de quais alterações podem ser realizadas na mistura para melhorá-la. Além disso, os testes de qualidade de coque, especialmente no que diz respeito à resistência mecânica, apresentam um caráter empírico que, apesar de prover resultados comparativos satisfatórios para a prática industrial, carecem de informações sobre as propriedades reais deste material.

Durante o processo de carbonização de carvões coqueificáveis, ocorrem uma série de transformações físico-químicas que inclui o estágio plástico. O estágio plástico é caracterizado pela simultânea liberação de matéria volátil e o amolecimento da massa carbonosa em função da formação de uma fase parcialmente líquida. Esta combinação é responsável pelo inchamento da massa plástica e a aglutinação de partículas, resultando na formação da matriz do coque. Os poros então são desenvolvidos durante o estágio plástico, visto que, durante a ressolidificação, as bolhas de gases dão lugar a eles [2]. No que diz respeito a composição maceral, carvões com elevada concentração de vitrinita, apresentam uma fase plástica de baixa viscosidade durante a carbonização, favorecendo a rápida expansão e coalescimento de bolhas. Por outro lado, o aumento de macerais do grupo da inertinita leva a diminuição da fluidez, devido ao aumento da viscosidade aparente. Resultando assim em uma microestrutura com menor porosidade e poros interconectados [3]. Por essas razões as propriedades termoplásticas e a composição maceral dos carvões exercem uma forte influência na formação da microestrutura porosa do coque. Além disso, sabe-se que a resistência mecânica está intimamente associada à microestrutura porosa do coque. Logo, compreender a influência das propriedades dos carvões na formação da microestrutura porosa nos auxilia a entender como ajustar uma dada mistura de carvões visando otimizar a qualidade do coque.

Foi desenvolvida no Laboratório de Siderurgia da UFRGS, uma ferramenta de análise de imagens visando a caracterização dos parâmetros microestruturais do 
coque a partir de imagens obtidas em microscópio ótico [4]. Esta ferramenta foi empregada no presente trabalho visando compreender a influência das propriedades dos carvões de origem na formação da microestrutura porosa do coque.

\section{MATERIAIS E MÉTODOS}

Coques do estudo: os coques laboratoriais utilizados foram produzidos a partir de carvões com propriedades distintas, visando obter propriedades microestruturais variadas entre os materiais estudados. A Tabela 1 apresenta a caracterização dos carvões utilizados. Segundo a norma ASTM D388, os carvões do estudo podem ser classificados como: A1 e A2 carvões betuminosos de alta matéria volátil, M1 e M2 carvões betuminosos de média matéria volátil e MC1 e MC2 misturas de carvões com médio teor de matéria volátil. A coqueificação em escala laboratorial foi realizada conforme descrito em Agra et al. (2019) [6].

Tabela 1. Caracterização dos carvões do estudo

\begin{tabular}{|c|c|c|c|c|c|c|c|c|c|c|}
\hline Carvões & $\begin{array}{c}M_{\text {bsic }} \\
(\%)\end{array}$ & $\begin{array}{c}\mathrm{Cz}_{\mathrm{bs}} \\
(\%)\end{array}$ & $\begin{array}{c}\mathrm{CF}_{\text {bs }} \\
(\%)\end{array}$ & $\begin{array}{l}\mathbf{R m} \\
(\%)\end{array}$ & $\begin{array}{c}\mathrm{V}_{\mathrm{Vol}, \%} \\
\text { imm }\end{array}$ & $\begin{array}{c}\text { Lvol, \% } \\
\text { imm }\end{array}$ & $\begin{array}{c}\text { I }^{*} \text { Vol, \% } \\
\text { imm }\end{array}$ & $\begin{array}{c}\mathrm{MM}_{\mathrm{Vol}}, \\
(\%)\end{array}$ & $\begin{array}{l}\text { IP } \\
(\stackrel{\circ}{ })()\end{array}$ & $\begin{array}{l}\text { log } \\
\text { MF }\end{array}$ \\
\hline A1 & 38,8 & 7,5 & 56,6 & 0,912 & 83,0 & 3,0 & 14,0 & 7,2 & 103 & 4,7 \\
\hline $\mathrm{A} 2$ & 36,8 & 6,8 & 58,8 & 0,841 & 78,0 & 10,0 & 11,9 & 4,4 & 84 & 4,1 \\
\hline M1 & 22,6 & 9,6 & 70,0 & 1,159 & 64,4 & 0,0 & 35,6 & 10,0 & 44 & 0,5 \\
\hline M2 & 22,8 & 9,5 & 70,0 & 1,207 & 81,3 & 0,4 & 18,3 & 7,2 & 77 & 2,4 \\
\hline MC1 & 27,6 & 8,7 & 66,0 & 1,018 & 78,8 & 0,9 & 20,3 & 7,6 & 78 & 2,4 \\
\hline MC2 & 22,5 & 6,5 & 72,5 & 1,119 & 60,1 & 3,4 & 36,5 & 10,8 & 78 & 2,5 \\
\hline
\end{tabular}

MV = Matéria volátil; Cz = Cinzas; CF = Carbono Fixo; bs = base seca; bsic = base seca isenta de cinzas; $\mathrm{Rm}=$ Refletância média da vitrinita; $V$ = Vitrinita; $L$ = Liptinita; I = Macerais do grupo da inertinita + coque de petróleo; $\mathrm{MM}=$ Matéria Mineral; \%Vol = percentual volumétrico; imm = isento de matéria mineral; IP = Intervalo Plástico; MF = Máxima Fluidez.

Destaca-se que os carvões A1 e A2 possuem, além do alto teor de matéria volátil, estágio plástico bastante desenvolvido (elevada máxima fluidez). Já os carvões M1 e MC2 possuem elevado teor de inertes, sendo o M1 devido ao conteúdo maceral do grupo da inertinita e o MC2 se deve (majoritariamente) à esta mistura ser composta por uma elevada quantidade do aditivo inerte coque de petróleo. O carvão M2 pode ser visto no presente estudo como uma referência de qualidade, pois é um carvão caracterizado comercialmente como premium.

\subsection{Caracterização Microestrutural dos Coques}

A caracterização da microestrutura porosa do coque foi realizada conforme a metodologia desenvolvida no Laboratório de Siderurgia da UFRGS cuja descrição detalhada pode ser encontrada em Agra et al. $(2018,2018,2019)[4,5,6]$. Segue aqui uma breve descrição e os principais parâmetros utilizados.

Foram preparados plugs para utilização em microscopia ótica a partir do embutimento, lixamento e polimento de 5 partículas de coque com granulometria entre 19,0 e 22,5 mm para cada amostra de coque. A área de análise por plug foi de $56,7 \mathrm{~mm}^{2}$, utilizando uma magnificação total de 50x (10x lente ocular e 5x lente objetiva). As imagens obtidas apresentaram uma resolução de 2500x1800 $\mu \mathrm{m}$ com resolução de 0,544 pixels/ $\mu \mathrm{m}$. A captura de imagem foi realizada em um microscópio ótico Leica DM6000 M. 
Os parâmetros microestruturais analisados pela técnica visando o presente estudo são apresentados na Tabela 2.

Tabela 2. Parâmetros microestruturais analisados.

\begin{tabular}{|c|c|c|}
\hline Parâmetros & Representação & Descrição \\
\hline Porosidade & & $\begin{array}{l}\text { Contagem de área ocupada por pixels } \\
\text { pretos em relação a área total considerada. }\end{array}$ \\
\hline $\begin{array}{l}D_{\text {eq }}=\text { Diâmetro } \\
\text { Equivalente }(\mu \mathrm{m})\end{array}$ & & $\begin{array}{l}\text { Diâmetro de um círculo perfeito que } \\
\text { equivale a área do poro - Fator de tamanho } \\
\text { de poro. }\end{array}$ \\
\hline $\mathrm{C}=$ Circularidade & & $\begin{array}{l}\text { Relação entre área }(A) \text { e perímetro }(P) \text {, } \\
\text { conforme: } C=4 . \pi \cdot A / P^{2} . C=1 \text { para círculos } \\
\text { perfeitos - Fator de forma de poro. }\end{array}$ \\
\hline $\mathrm{F}=$ Relação Feret & & $\begin{array}{l}\text { A razão entre as retas mais distantes e } \\
\text { mais próximas que tangenciam o contorno } \\
\text { de um objeto - Fator de forma de poro. }\end{array}$ \\
\hline
\end{tabular}

\subsection{Relação Entre Parâmetros Microestruturais e Propriedades dos Carvões de Origem}

As propriedades dos carvões foram relacionadas com os parâmetros da Tabela 2 buscando compreender a formação da microestrutura. Assim, foram avaliadas a influência das propriedades termoplásticas (máxima fluidez), teor de matéria volátil e relação reativo/inerte $(\mathrm{R} / \mathrm{l})$ dos carvões na porosidade, tamanho de poro (Deq) e forma (C e F).

\subsection{Convergência dos Parâmetros Microestruturais com Modelos de Qualidade do Coque}

Após a caracterização microestrutural dos coques estudados, buscou-se comparar os resultados obtidos com outros modelos de previsão de qualidade de coque, o modelo do índice ideal de inerte - $\mathrm{CBI}$, o diagrama MOF e o volume de poros críticos (critérios segundo Agra et al. (2019) [6].

\section{RESULTADOS E DISCUSSÕES}

\subsection{Caracterização Microestrutural dos Coques}

Os resultados da caracterização microestrutural dos coques são apresentados na Tabela 3. Já na Figura 1, é apresentado as microestruturas porosas das amostras dos coques gerados, sendo que as regiões em branco na imagem representam a matriz carbonosa e as regiões em preto representam os poros. É possível observar nesta figura as mesmas tendências dos parâmetros microestruturais avaliados quantitativamente na Tabela 3. 
Tabela 3. Resultados dos parâmetros microestruturais analisados.

\begin{tabular}{cccccc}
\hline $\begin{array}{c}\text { Carvão/mistura } \\
\text { de origem }\end{array}$ & Coque & $\begin{array}{c}\text { Porosidade } \\
(\%)\end{array}$ & $\begin{array}{c}\mathbf{D}_{\text {eq }} \\
(\boldsymbol{\mu m})\end{array}$ & $\mathbf{C}$ & $\mathbf{F}$ \\
\hline $\mathrm{A} 1$ & $\mathrm{C}_{\mathrm{A} 1}$ & 66,4 & 257,1 & 0,53 & 1,58 \\
$\mathrm{~A} 2$ & $\mathrm{C}_{\mathrm{A} 2}$ & 64,4 & 258,6 & 0,63 & 1,54 \\
M1 & $\mathrm{C}_{\mathrm{M} 1}$ & 44,5 & 188,7 & 0,40 & 1,62 \\
M2 & $\mathrm{C}_{\mathrm{M} 2}$ & 51,0 & 219,4 & 0,49 & 1,61 \\
MC1 & $\mathrm{C}_{\mathrm{MC} 1}$ & 57,6 & 212,0 & 0,41 & 1,60 \\
MC2 & $\mathrm{C}_{\mathrm{MC2}}$ & 47,4 & 212,9 & 0,32 & 1,63 \\
\hline
\end{tabular}

Deq $=$ Diâmetro Equivalente Médio; $\mathrm{C}=$ Circularidade; $\mathrm{F}=$ Fator de Feret.

Conforme pode ser observado na Tabela 3, a porosidade variou entre 44,5 e $66,4 \%$ e o diâmetro equivalente, parâmetro que descreve o tamanho médio dos poros, variou entre 188,7 e 257,1 $\mu \mathrm{m}$. Os carvões com alto teor de matéria volátil (A1 e A2) deram origem aos coques de maior porosidade (66,4 e 64,4\%, respectivamente) e com poros de maior diâmetro equivalente (257,1 e 258,6 $\mu \mathrm{m})$. Já os oriundos de carvões médio volátil ( $\mathrm{C}_{\mathrm{M}_{1}}$ e $\mathrm{C}_{\mathrm{M} 2}$ ) apresentam uma microestrutura com baixa porosidade e poros de tamanho médio pequeno. Por fim, as misturas (MC1 e MC2) formam coques com uma microestrutura com parâmetros intermediários.

Quanto aos fatores de forma, a relação de Feret variou entre 1,54 e 1,63 e a circularidade entre 0,32 e 0,63 . Os carvões com alto teor de inertes (M1 e MC2) deram origem aos coques com maior $F(1,62$ e 1,63) e menor circularidade $(0,40$ e $0,32)$, ou seja, as piores formas observadas no estudo. A relação destas propriedades com os carvões de origem será explorada mais profundamente no próximo item.
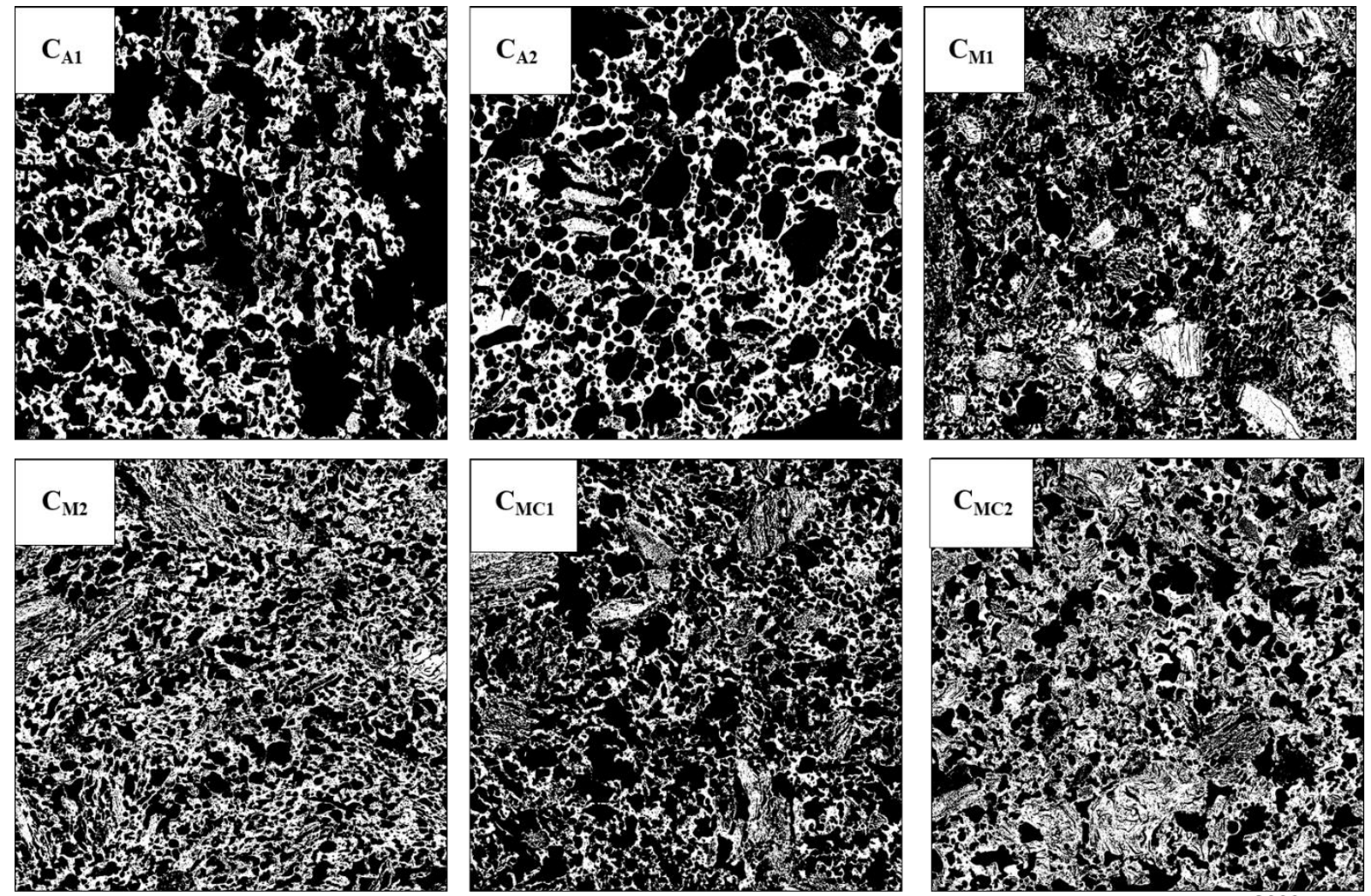

$2000 \mu \mathrm{m}$

Figura 1. Microestrutura porosa resultante dos coques produzidos. 


\subsection{Relação Entre Parâmetros Microestruturais e Propriedades dos Carvões de Origem}

Efeito das propriedades dos carvões na Porosidade dos coques: Conforme discutido anteriormente, os parâmetros operacionais do processo de coqueificação e as propriedades dos carvões de origem são os principais fatores que influenciam na formação da microestrutura porosa do coque. A influência dos carvões de origem pode ser explicada pelos fenômenos que ocorrem durante o estágio plástico. No processo de coqueificação, ocorre uma formação parcial de líquido e amolecimento da carga. Simultaneamente, ocorre o desprendimento de matéria volátil. A combinação dos fenômenos de amolecimento e desvolatilização culminam na formação da macroporosidade do coque. Na Figura 2 são apresentadas as relações entre as propriedades dos carvões e a porosidade dos coques.
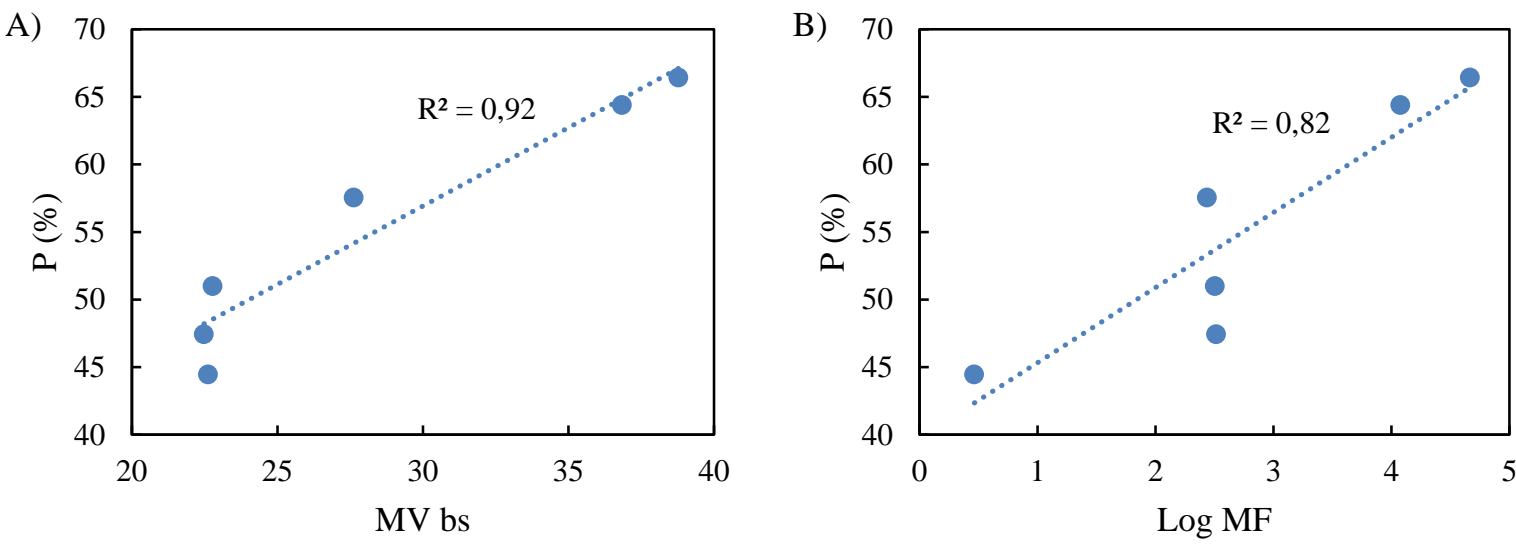

Figura 2. Relações entre teor de matéria volátil (A) e máxima fluidez (B) dos carvões com a porosidade dos coques resultante.

A matéria volátil apresentou elevada correlação com a porosidade $\left(R^{2}=0,92\right)$, o que corrobora com a importância desta propriedade na formação da macroporosidade do coque. Já a relação entre máxima fluidez e porosidade apresentou um coeficiente de determinação de 0,82 . É interessante observar que as misturas MC1 e MC2 apresentam máxima fluidez semelhante $\left(2,4\right.$ e 2,5), porém os coques $\mathrm{C}_{\text {MC1 }}$ e $\mathrm{C}_{\mathrm{MC} 2}$ diferem significativamente em termos de porosidade (57,6 e 47,4\%). Dois pontos podem ser elencados como responsáveis por essa ocorrência: (1) as misturas estudadas são compostas por carvões com uma variedade muito grande de propriedades (MV, MF e R/l), algumas conhecidamente não aditivas [7], de forma que o comportamento médio (resultado dos ensaios de caracterização) talvez não seja suficiente para relacionar com a porosidade dos coques; (2) os diferentes tipos de componentes inertes presentes nas misturas de carvões tem comportamento distinto na carbonização, impactando de forma diferente nos parâmetros microestruturais. Os inertes orgânicos, como macerais do grupo da inertinita, possuem forte influência na no estágio plástico dos carvões durante a carbonização, atuando como supressores das propriedades termoplásticas [8, 9]. No entanto, outros tipos de aditivos, como o coque de petróleo (em alta concentração na mistura MC2), possuem comportamento diferente na carbonização, contribuindo de maneira não desprezível no desenvolvimento de estágio plástico dos carvões [10].

De um modo geral, para os coques gerados por carvões individuais, foi possível observar que a presença de alto teor de matéria volátil e de elevada plasticidade 
resultam em coques de elevada porosidade (> $60 \%$ ), enquanto coques oriundos de carvões com médio teor de matéria volátil produziram coques com menor porosidade (aproximadamente $50 \%$ ).

Efeito das propriedades dos carvões no tamanho dos poros: Na Figura 3 é apresentado a relação entre máxima fluidez e relação reativo/inerte dos carvões de origem no diâmetro equivalente médio dos coques (fator de tamanho).
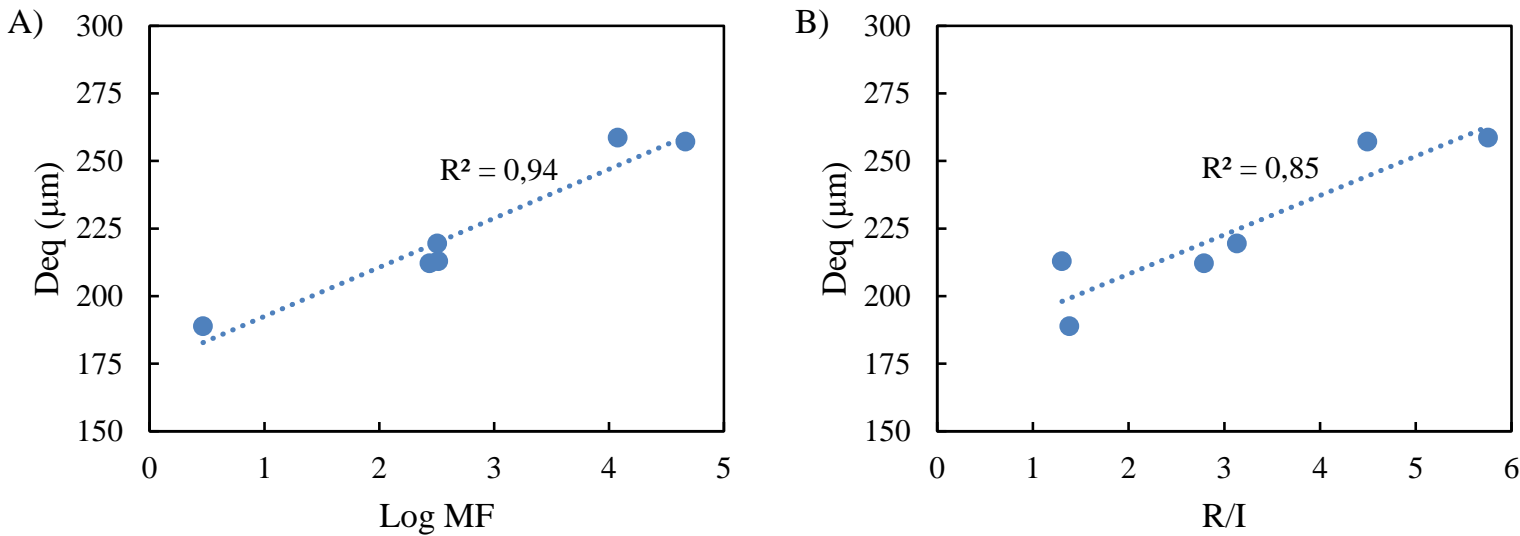

Figura 3. Relações entre teor de matéria volátil $(A)$ e relação reativo/inerte $(B)$ dos carvões de origem com o diâmetro equivalente médio dos poros dos coques resultante.

Conforme pode ser observado na Figura 3a, o $D_{\text {eq }}$ é fortemente influenciado pelas propriedades termoplásticas (máxima fluidez) e de teor de matéria volátil (Tabela 4). Esta influência se justifica nos fenômenos do estágio plástico, pois conforme observado nos estudos de Toishi et al. (2013) [11], a concomitância de elevados níveis de fluidez e de teor de matéria volátil possibilita um maior crescimento e coalescimento das bolhas de gás durante o processo de coqueificação. Como pode ser visto na Figura $3 b$, a relação entre componentes reativos/inertes também apresenta forte influência neste parâmetro, pois quanto maior a concentração de componentes reativos, maior é a plasticidade dos carvões, contribuindo na formação de poros grandes. Por outro lado, para carvões com baixa relação reativos/inertes, se observa uma microestrutura porosa composta por poros menores [3], porém, como será discutido posteriormente, um elevado teor de inertes impacta nos parâmetros de forma dos poros.

Efeito das propriedades dos carvões na forma dos poros: A Figura 4 apresenta a relação da matéria volátil e relação reativo/inerte dos carvões de origem com o fator de forma de poros $F$ (relação de Feret). 

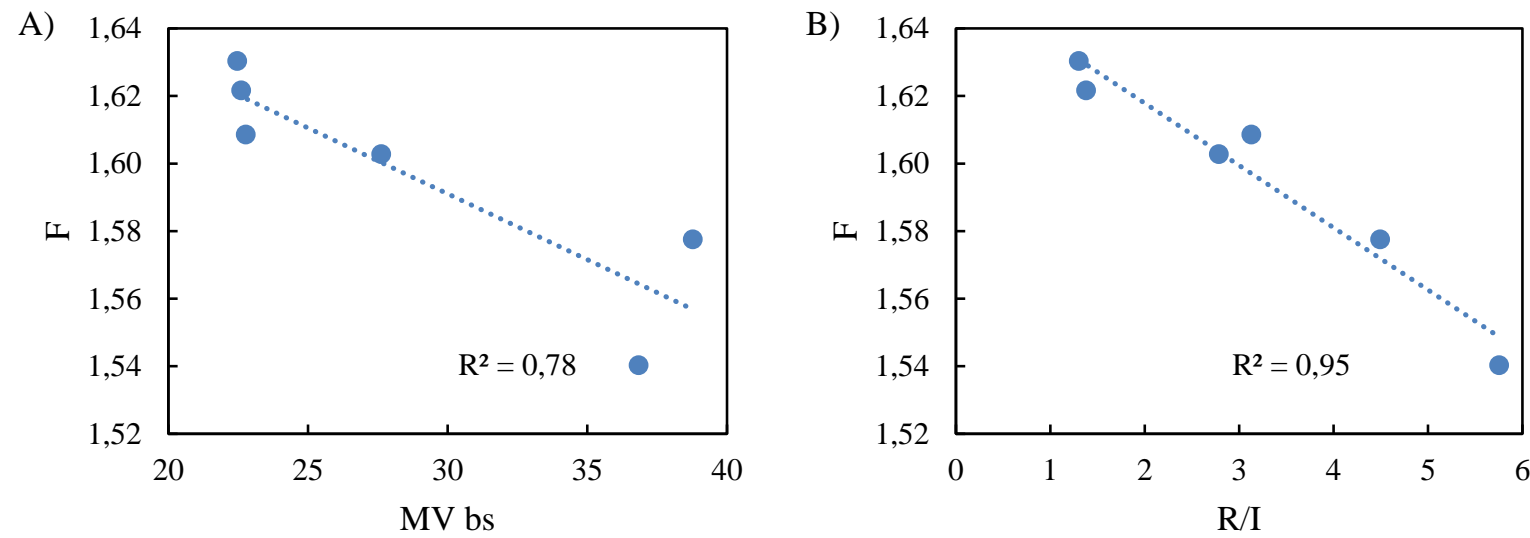

Figura 4. Relações entre teor de matéria volátil $(A)$ e relação reativo/inerte $(B)$ dos carvões de origem com a relação de Feret $(F)$ dos coques resultantes.

De forma geral, pode-se observar que a forma dos poros é prejudicada (maior relação Feret) em coques gerados por carvões com baixo teor de matéria volátil e com baixa relação reativo/inerte. Dois mecanismos podem ser sugeridos como responsáveis pela piora da forma dos poros com o aumento do teor de inertes nos carvões: (1) durante a formação dos poros, no estágio plástico do processo de coqueificação, os inertes podem atuar ancorando as bolhas de gases formadas, dificultando a livre expansão, e consequentemente formando poros irregulares. (2) a redução da plasticidade local, em função da presença de inertes favorece a formação de poros aciculares. Nota-se que a relação R/l se apresenta como principal fator influenciando na forma dos poros. Maiores detalhes acerca deste tema podem ser encontrados em Kubota et al. (2011) [12].

Sumarização das relações: Na Tabela 5 são apresentados todos os coeficientes de determinação obtidos nas relações entre parâmetros microestruturais e propriedades de carvões sumarizando os resultados deste item.

Tabela 5. Coeficientes de determinação das relações entre propriedades de carvões e parâmetros microestruturais.

\begin{tabular}{lccc}
\hline & $\log \mathbf{M F}$ & $\mathbf{M V}$ bs & $\mathbf{R / I}$ \\
\hline Porosidade $(\mathbf{P})$ & 0,82 & 0,92 & 0,82 \\
Diâmetro equivalente $\left(\mathbf{D}_{\text {eq }}\right)$ & 0,94 & 0,83 & 0,85 \\
Feret (F) & 0,55 & 0,78 & 0,95 \\
\hline ez; MV = Matéria volátili; Cz = Cinzas; bs = base seca; R/I = Relação reativo/inerte.
\end{tabular}

Destaca-se na Tabela 5 que o coeficiente de determinação entre máxima fluidez e fator de forma não foi consideravelmente alto. No entanto, ao observarmos os resultados dos coques na Tabela 3 , nota-se uma convergência com o exposto até aqui. Os coques dos carvões A1 e A2 apresentando um baixo fator $F(1,58$ e 1,54$)$ e o coque do carvão M1, que possui uma menor fluidez e um elevado teor de inertes, apresentou um elevado fator $F(1,62)$. Ou seja, existe uma clara tendência entre máxima fluidez e forma dos poros, porém, esta propriedade sozinha não consegue descrever as variações na forma dos poros. 


\subsection{Convergência dos Parâmetros Microestruturais com Outros Modelos de Qualidade do Coque}

Índice ideal de inertes (Composition Balance Index - CBI): este modelo sugere que há uma relação ideal entre o conteúdo de componentes reativos e inertes para um carvão de um dado rank. Essa relação ideal seria responsável pela maximização da resistência mecânica a frio do coque. $\mathrm{O}$ índice $\mathrm{CBI}$ é calculado pela razão entre os componentes inertes existentes no carvão com o conteúdo ideal teórico. O cálculo foi realizado conforme o modelo desenvolvido por Shapiro et al. (1961) [13] e é apresentado na Tabela 6.

Tabela 6. Índice ideal de inertes (CBI) dos carvões estudados.

\begin{tabular}{ccccccc}
\hline Carvão & A1 & A2 & M1 & M2 & MC1 & MC2 \\
\hline CBI & 0,6 & 0,5 & 2,4 & 1,2 & 1,1 & 2,6 \\
\hline
\end{tabular}

A relação dos parâmetros microestruturais dos 'coques com o índice $\mathrm{CBI}$ é apresentada na Figura 5.
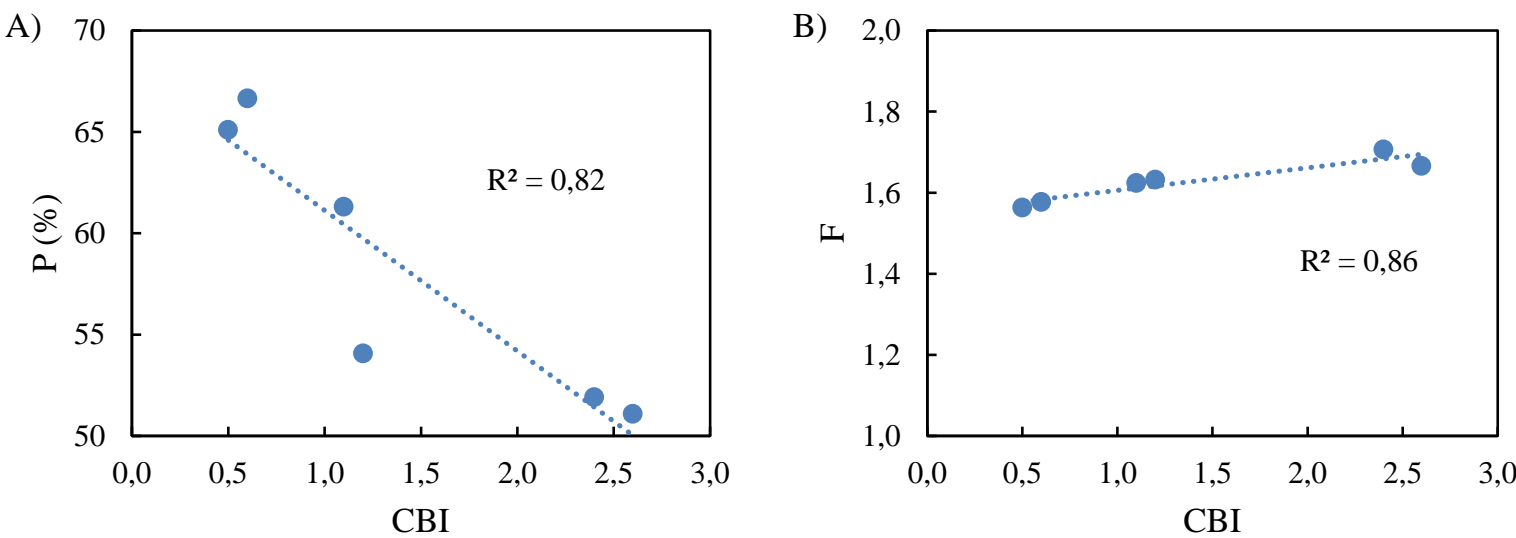

Figura 5. Relações entre o índice $C B I$ com os parâmetros de porosidade (A) e Feret (B).

Os resultados das relações observadas na Figura 5 indicam que carvões com escassez de inertes $(\mathrm{CBI}<1)$ resultam em coques com elevada porosidade. Por outro lado, carvões com $\mathrm{CBI}>1$, ou seja, com excesso de inertes, geram coques com baixa porosidade. Estas observações estão de acordo com o modelo de Schapiro et al (1961) [13]. Porém, nestes mesmos carvões, a forma dos poros é menos adequada (alta relação de Feret). Nota-se que carvões com CBI próximo a unidade originam coques com porosidade intermediária e com forma de poro adequada.

Diagrama MOF: o diagrama MOF considera que o rank e a fluidez dos carvões de origem governam a resistência mecânica. Neste modelo, estima-se que para um coque apresentar resistência mecânica elevada, os carvões devem apresentar rank entre 1,2 e 1,3 e máxima fluidez entre 200 e 1000 ddpm [14]. Conforme discutido anteriormente, devido à dificuldade em relacionar as propriedades de misturas de carvões com parâmetros microestruturais, neste tópico apenas serão tratados os carvões individuais e os coques produzidos por eles. A discussão será realizada com base nas propriedades de refletância média da vitrinita e máxima fluidez da 
Tabela 2, bem como os parâmetros microestruturais de porosidade, diâmetro equivalente médio e relação de Feret da Tabela 3.

Os carvões de alto-volátil possuem rank $(\mathrm{Rm})$ inferior ao visado como ideal, bem como máxima fluidez superior ao desejado. Assim, a caracterização dos coques gerados por estes carvões resulta em uma microestrutura altamente porosa e com poros grandes. Já o carvão M1, apesar de apresentar Rm próximo ao esperado, este material apresenta uma fluidez escassa. De acordo com estas propriedades, a microestrutura apresentada no coque $\mathrm{C}_{\mathrm{M} 1}$ se mostrou de baixa porosidade e fator de forma $\mathrm{F}$ inadequado, apesar de ter apresentado um $\mathrm{D}_{\text {eq }}$ baixo. Por fim, o carvão M2 foi o único a apresentar rank e fluidez dentro do ideal proposto pelo diagrama MOF. Logo, o coque $\mathrm{C}_{\mathrm{M} 2}$ apresentou a microestrutura mais adequada entre os coques estudados, com baixa porosidade, poros pequenos e formas adequadas.

Volume de poros críticos: A metodologia apresentada em Agra et al. (2019) [6] classifica os poros quanto críticos ou não para a resistência mecânica do material. $O$ modelo define, baseado na literatura, que poros com $\mathrm{D}_{\text {eq }}>300 \mu \mathrm{m}$ são críticos em função do tamanho e poros com $c<0,2$ são críticos devido a sua forma (acentuadamente aciculares). Na Figura 6 buscou-se verificar a relação entre máxima fluidez com poros críticos por tamanho e a relação $\mathrm{R} / \mathrm{l}$ com poros críticos por forma.
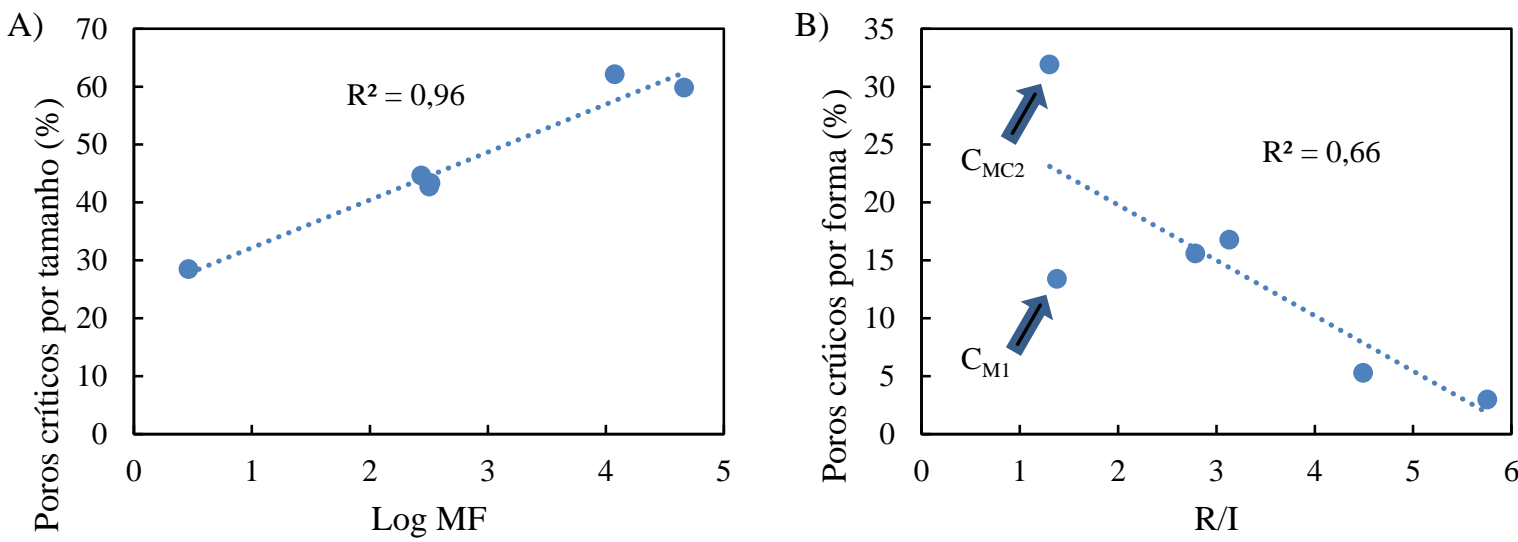

Figura 6. (A) Relação entre máxima fluidez e fração volumétrica de poros críticos por área. (B) Relação entre R/l e fração volumétrica de poros críticos por forma.

Na Figura 6a é possível observar a influência das propriedades termoplásticas (MF) na fração de volume total de poros críticos por área. Conforme já apresentado no presente estudo, propriedades termoplásticas desenvolvidas induzem a formação de uma microestrutura porosa com poros grandes. Logo, um maior valor de máxima fluidez acarreta em um maior volume de poros excessivamente grandes, que comprometem a qualidade do coque. Já na Figura $6 b$ é apresentada a influência da relação R/I no volume total de poros críticos por forma. Nota-se uma tendência geral de um aumento do volume de poros críticos por forma com o aumento do teor de inertes no carvão, concordando com o discutido no item sobre os efeitos das propriedades dos carvões na forma dos poros. No entanto, o coeficiente de determinação não foi tão elevado. A essa discrepância pode-se atribuir a diferença significativa do volume de poros críticos por forma entre os coques $\mathrm{C}_{\mathrm{M} 1}$ e $\mathrm{C}_{\mathrm{MC} 2 \text {, cujos }}$ carvões de origem apresentam uma relação R/l bastante similar. Para fins de comparação, a regressão entre poros críticos por forma e relação $R / /$ excluindo o 
coque $\mathrm{C}_{\mathrm{M} 1}$ possui um $\mathrm{R}^{2}$ de 0,92 . A diferença observada pode estar associada a influência dos diferentes tipos de inertes presente em cada carvão, pois os inertes diferem em composição química, morfologia e tamanho. O carvão M1 é rico em inertinita, já a mistura MC2 possui um grande teor de coque de petróleo como aditivo inerte. Tais motivos podem explicar a diferença observada e maiores estudos sobre o tema devem ser realizados.

\section{CONCLUSÃO}

Este estudo buscou apresentar as relações entre as propriedades dos carvões estudados com os parâmetros microestruturais dos coques, que foram avaliados através da metodologia desenvolvida no Laboratório de Siderurgia da UFRGS. Foi possível verificar que a formação da microestrutura porosa dos coques é governada pelas propriedades dos carvões, especialmente propriedades termoplásticas e de composição maceral, o que é corroborado por estudos anteriores.

Foi possível verificar no presente estudo, apoiado em outros modelos de previsão de qualidade de coque, as seguintes observações:

- $\quad$ Carvões com estágio plástico desenvolvido (MF > 1000 ddpm), com elevado teor de matéria volátil (>30 \%) e com índice $\mathrm{CBI}<1$, tendem a gerar coques de alta porosidade e com tamanho médio de poro excessivo.

- Carvões de baixa fluidez (MF < 200 ddpm) e com alta concentração de inertes $(\mathrm{R} / \mathrm{I}<1.4$ e $\mathrm{CBI}>1)$, resultam em coques com poros pequenos e baixa porosidade, porém com elevada relação de Feret (forma inadequada).

- Os carvões com as melhores propriedades (critérios dos modelos MOF e $\mathrm{CBI}$ ) resultaram nos coques com as microestruturas mais regulares, de baixa porosidade, com pequenos poros e com formatos adequados.

A compreensão da influência das propriedades dos carvões na formação da microestrutura porosa mostra-se uma ferramenta importante para estimar possíveis alterações de misturas visando otimizar a qualidade do coque.

\section{Agradecimentos}

Os autores desse trabalho agradecem a Gerdau Açominas pelo fornecimento dos carvões importados e ao Conselho Nacional de Desenvolvimento Científico Tecnológico (CNPq) pelo incentivo financeiro e aos bolsistas de iniciação científica Jamile Guarda e Gustavo Marques de Oliveira pelo auxílio nos ensaios realizados.

\section{REFERÊNCIAS}

1 Coelho RJ, Silva OJ, Alves MT, Andrade LA, Assis PS. Modelos de Previsão da Qualidade Metalúrgica do Coque a Partir das Qualidades dos Carvões Individuais e do Coque Obtido no Forno-Piloto de Coqueificação. Revista Escola de Minas. 2004;57;2732.

2 Patrick JW, Hanson S. Pore Structure of Graphite, Coke and Composites. Handbook of Porous Solids. 2002;3;1900-1922.

3 Steel KM, Dawson RE, Jenkins DR, Pearce R, Mahoney MR. Use of Rheometry and Micro-CT Analysis to Understand Pore Structure Development in Coke. Fuel Processing Technology. 2017;155;106-113. 
4 Agra AA, Flores BD, Nicolodi A, Silva GLR, Vilela ACF, Osório E. Microestrutura do Coque: Desenvolvimento de Análise Quantitativa Via Microscopia Ótica Associada a Análise de Imagem. 47ํㅗㄴ Seminário de Redução de Minérios e Matérias-Primas, ABM Week. 2018.

5 Agra AA, Flores BD, Vilela ACF, Osório E, Silva GLR. Coke microstructure - sample preparation and image analysis via ImageJ. 8 th International Council for Scientific and Technical Information (ICSTI), Vienna. 2018.

6 Agra AA. Microestrutura Porosa do Coque: Dependência das Propriedades dos Carvões de Origem e Relação com a sua Resistência Mecânica. Dissertação de Mestrado, Universidade Federal do Rio Grande do Sul. Porto Alegre. 2018

7 Gums A, Flores BD, Agra AA, Silva GLR, Vilela ACF Osório E. Estudo das Interações Entre Carvões no Desenvolvimento Plástico de Misturas Contendo Carvão Nacional. 47ํ Seminário de Redução de Minérios e Matérias-Primas, ABM Week. 2018.

8 Fernandez AM, Barriocanal C, Díez MA, Alvarez R. Importance of the Textural Characteristics of Inert Additives in the Reduction of Coal Thermoplastic Properties. Fuel. 2010;88;2365-2372.

9 Loison R, Foch P, Boyer A. Coke Quality and Production. London: 2nd ed.Butterworth \& CO;1989.

10 Menéndez JA, Pis JJ, Alvarez R, Barriocanal C, Fuente E, Díez MA. Characterization of Petroleum Coke as an Additive in Metallurgical Cokemaking. Modification of Thermoplastic Properties of Coal. Energy \& Fuels. 1996;10(6);1262-1268.

11 Toishi A, Yamazaki Y, Uchida A, Saito Y, Aoki H, Nomura S, Arima T, Kubota Y, Hayashizaki H. Quantitative Evaluation for Relationship Between Development of Pore Structure and Swelling of Coal in Carbonization of Single Coal Particle. ISIJ. 2013;53;1739-1748.

12 Kubota Y, Nomura S, Arima T, Kato K. Quantitative Evaluation of Relationship Between Coke Strength and Pore Structure. ISIJ. 2011;51(11);1800-1808.

13 Shapiro N, Gray RJ, Eusner GR. Recent Developments in Coal Petrography. Blast Furnace, Coke Oven and Raw Materials Conference. 1961.

14 Díez MA, Alvarez R, Barriocanal C. Coal for metallurgical coke production: Predictions of coke quality and future requirements for cokemaking. International Journal of Coal Geology. 2002;50(1-4);389-412. 